\title{
OA08.03. Electroacupuncture alleviates hyperalgesia by inhibiting spinal interleukin-17 in an inflammatory pain rat model
}

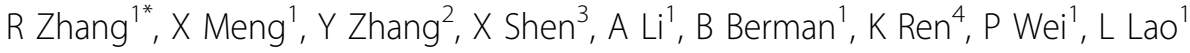 \\ From International Research Congress on Integrative Medicine and Health 2012 \\ Portland, Oregon, USA. 15-18 May 2012
}

\section{Purpose}

Previous studies demonstrated that electroacupuncture (EA) alleviates hyperalgesia, but the mechanisms remained unclear. Because it is well known that interleukin-17 (IL-17) is associated with autoimmune disorders, the present study was designed to determine whether spinal IL-17 plays a role in inflammatory pain and, if so, whether EA inhibits spinal IL-17 expression during such pain.

\section{Methods}

Hyperalgesia was induced by injecting complete Freund's adjuvant (CFA, $0.08 \mathrm{ml}, 40 \mu \mathrm{g}$ Mycobacterium tuberculosis) into one hind paw of each rat. EA treatment, $10 \mathrm{~Hz}$ at $3 \mathrm{~mA}$, was given at acupoint GB30 twice for 20 min each, once immediately post-CFA and again 2 hours later. Paw withdrawal latency (PWL) was tested before $(-48 \mathrm{~h})$ and 2 and 24 hours after CFA to assess behavioral hyperalgesia. IL-17 antibody $(0.2-2 \mu \mathrm{g} / \mathrm{rat})$ was given intrathecally (i.t.) $24 \mathrm{~h}$ before CFA to block the action of basal IL-17 and 2 hours prior to each of two PWL tests to block CFA-induced IL-17. I.t. recombinant IL-17 (10-400 ng/rat) was administered to naive rats to determine its effects on PWL and phosphorylation of NR1 (p-NR1). P-NR1 is known to modulate Nmethyl-D-aspartate receptor (NMDAR) activity and to facilitate pain. Spinal cords were removed for immunostaining of IL-17, double immunostaining of IL-17/cell markers and IL-17 receptor subtype A (IL-17RA)/NR1, and western blot to measure p-NR1 and IL-17RA.

\section{Results}

The data showed that (1) IL-17 is selectively up-regulated in astrocytes, 2) IL-17RA is localized and up-regulated in NR1-immunoreactive neurons, and 3) an IL-17 antibody at $2 \mu \mathrm{g} /$ rat significantly increased PWL $(\mathrm{p}<0.05)$ and decreased $\mathrm{p}-\mathrm{NR} 1$ and IL-17RA in CFAand IL-17-injected rats compared to control. EA significantly inhibited hyperalgesia, IL-17, IL-17RA, and pNR1.

\section{Conclusion}

The results suggest that (1) spinal IL-17 is produced by astrocytes and enhances p-NR1 to facilitate inflammatory pain, and 2) EA inhibits hyperalgesia by suppressing IL-17.

\section{Author details}

${ }^{1}$ Center for Integrative Medicine, Baltimore, USA. ${ }^{2}$ Department of Neurobiology, Shanxi Medical University, Taiyuan, China. ${ }^{3}$ Shanghai University of Traditional Chinese Medicine, Shanghai, China. ${ }^{4}$ Dept. of Neural and Pain Sciences, Dental Sch., Univ. of Maryland, Baltimore, USA.

Published: 12 June 2012

doi:10.1186/1472-6882-12-S1-031

Cite this article as: Zhang et al:: OA08.03. Electroacupuncture alleviates hyperalgesia by inhibiting spinal interleukin-17 in an inflammatory pain rat model. BMC Complementary and Alternative Medicine 2012 12(Suppl 1): O31.

${ }^{1}$ Center for Integrative Medicine, Baltimore, USA

Full list of author information is available at the end of the article

(c) 2012 Zhang et al; licensee BioMed Central Ltd. This is an Open Access article distributed under the terms of the Creative Commons Attribution License (http://creativecommons.org/licenses/by/2.0), which permits unrestricted use, distribution, and reproduction in any medium, provided the original work is properly cited. 